\title{
“Service Programmes" on Jordanian Radio: Understanding Broadcaster Persona through an Interdisciplinary Analysis of Language and Performance
}

\author{
MENACS Graduate Conference, University of Sussex, UK
}

28 April 2017

\author{
Jona Fras \\ PhD Candidate \& Teaching Fellow in Arabic \\ Department of Islamic and Middle Eastern Studies, The University of Edinburgh \\ 19 George Square, Edinburgh EH8 9LH \\ jona.fras@ed.ac.uk
}

\begin{abstract}
Radio stations in contemporary Jordan broadcast what is locally known as morning "service programmes" (barāmij khadamātiyya), in which listeners call the station and speak live on air in order to request assistance or ask for mediation with local authorities in resolution of an issue. As part of my doctoral research on communicative discourse in Jordanian radio today, I analyse the "persona" of the broadcasters who respond to these calls and communicate with listeners as a crucial element that makes service programmes distinctive from each other.

I compare and contrast the personae of two service programme hosts, Hani al-Badri and Muhammad al-Wakeel, through analysing programme recordings and accompanying data from websites and social media. I argue, however, that an adequate exploration of such media texts requires an interdisciplinary theoretical and methodological approach, including theory and methods from:
\end{abstract}

a) sociolinguistics - detailed analysis of transcripts and phoneme frequencies in radio programme recordings;

b) linguistic anthropology - analysing radio programme recordings as culturally specific types of communication affected by particular concepts of style, genre, and performance; 
and c) media studies - interpreting radio recordings as a type of mass- mediated communication.

One challenge of this approach lies in choosing data and material that is amenable to multi-stranded analysis. It also runs the risk of sacrificing methodological rigorosity, as defined by each individual discipline, in favour of a more sweeping examination with a less clearly defined focus.

Nevertheless, I argue that setting the scope more broadly is productive in the case of analysing Jordanian radio programme recordings. My study demonstrates that minute aspects of language and performance have broader relevance through public address and participation frameworks. An interdisciplinary approach, therefore, reveals important aspects of media communication in the contemporary Middle East which may be neglected when the topic is approached through a single disciplinary lens.

\section{Introduction}

My ESRC-funded doctoral research explores linguistic practice on Jordanian radio today. The main conclusion of my research is that details of Arabic use in the radio setting have significant implications for the kind of audiences addressed - that is, who is included as a legitimate or "validated" listener - and the way members of the public can participate in radio discourse - this latter in particularly through call-ins, which are a frequent feature of Jordanian radio programming more generally.

This paper looks at one type of programmes present on many contemporary Jordanian radio stations: the so-called "service programmes," barāmiž ḳadamātiyya, in which listeners call the station and speak live on the air in order to request assistance or mediation with local authorities in resolution of an issue - such as a damaged road, a broken water pipe, et cetera. It compares two popular service programmes: Barnāmiž al-wakīl, hosted by Muhammad al-Wakeel, and Wasaț al- 
balad, hosted by Hani al-Badri. It argues that, in order to properly appreciate the differences between the two programmes, an interdisciplinary approach to the data is required. This has raised certain methodological issues for my work, but on the other hand allowed me to explore new theoretical pathways and contribute new insights to scholarship on both contemporary Arabic language use, and Middle Eastern media.

\section{The service programme genre}

On Jordanian radio, service programmes form a distinctive "genre" in that they involve a number of features which distinguish them from other types of programming. These features include:

a) scheduling - they are usually broadcast in the morning, between 7 and 10 AM;

b) liveness - they are always broadcast live, never pre-recorded;

c) they deal with news and current affairs - usually with a "news headline" segment in which the host reads out headlines from newspapers and websites;

d) music background - they include a significant amount of contemporary Jordanian nationalist or patriotic songs (so-called aġānī wațaniyya). This serves as a strong index that they are "meant for" a Jordanian national audience, that they "serve" Jordanians alone. 
e) finally, they involve live call-ins from listeners. Most of these calls are "service calls," in which listeners request some sort of service from the broadcaster. Often this involves the broadcaster contacting a local authority to resolve a problem, such as a damaged road or (the most cliché example) a broken water pipe.

As part of my doctoral research, I analysed two service programmes in particular: Barnāmiž al-wakīl, hosted by Muhammad al-Wakeel on Radio Hala (the radio station of the Jordanian army), and Wasat al-balad, hosted by Hani al-Badri on the commercial radio station Radio Fann. These are very popular programmes, always inundated with calls, and with significant followings on social media - the hosts have personal websites on Facebook with thousands, or in al-Wakeel's case millions, of followers.

My interest was, however, specifically on the spoken language aspect of the programmes. What kind of language do the hosts use when they address listeners and communicate with callers? And does this have broader implications for the role these programmes play in the Jordanian social, political, and cultural context? Commenters such as Salam al-Mahadin have written that such programmes essentially support the Jordanian regime's nationalist project, promoting images of authentic, exclusive Jordanian-ness through use of certain sounds - such as [g] for [q] (qāf; as in the word bigūl for "he says" in local Colloquial Arabic). [Al-Mahadin 2016] I wanted to explore the extent to which this was actually the case in practice, by looking at the language used on service programmes in more detail. 


\section{The methodological problem: from sociolinguistics to linguistic}

\section{anthropology}

The issue arose, however, on how to actually do this methodologically. One established method in studies of spoken media Arabic is variationist sociolinguistic analysis, in which the occurrence of words or phonemes is counted and tabulated in order to "map" a speaker's affiliation to identity categories, such as gender, age, or ethnicity. This type of analysis can be highly informative for studying, for example, language shift, as in Enam al-Wer's studies on the formation of a distinct "Ammani dialect" in Jordan in the second half of the $20^{\text {th }}$ century. [al-Wer 2007]

As part of my research, I did in fact run a frequency analysis on the language used by service programme hosts. I analysed 30 minutes of "pure talk" selected randomly from a total of around 40 hours of recordings of Muhammad al-Wakeel and Hani al-Badri's service programmes. I compared their language for several meaningful variables, including (q) (qāf / gāf) and (ž) (žīm / džīm). Here the results were remarkably similar: both hosts did, indeed, use [g] quite heavily, and also used the variant [d3] (the more "authentic," locally Jordanian marked variant) for žīm. Both these versions are locally understood as the more forceful / "masculine" variant, but also more authentically Jordanian - contrasting with other Levantine dialects such as Palestinian, Syrian, or Lebanese, which use different pronunciations.

Yet the fact remains that al-Wakeel and al-Badri's programmes are remarkably different when one listens to them. It was clear that I had to go beyond sociolinguistics in order to properly acknowledge this fact. I thus drew on a method from linguistic anthropology, what Susan Philips has termed "anthropological discourse analysis," or the "comparative study of units of interaction." [Philips 2013] This method involves the 
comparative analysis of large amounts of linguistic data - such as recordings or, indeed, radio programme transcripts - identifying patterns in usage habits and critically singling out interesting cases for more detailed analysis.

This method has revealed that, although al-Badri and al-Wakeel might be quite similar from a variationist sociolinguistic perspective, they nevertheless differ, in two segments of their radio performances in particular:

a) First of these are monologues where broadcasters offer their views on pecific issues. Both broadcasters self-evaluate - in John Du Bois's terms, they perform an "evaluative stance" [Du Bois 2007] towards their own talk as "authentic" speakers not influenced by government or official presures. However, al-Wakeel's linguistic performance builds on concepts of forcefulness and agency and implies that he is a strong, independent actor all on his own. al-Badri, by contrast, uses more stylised, ironic, and joking linguistic strategies much more frequently, thereby presenting himself as an "ordinary citizen" not involved in government machinations.

b) service calls. Here again al-Wakeel reinforces his status as a "problemsolver"; he always reassures callers their problems will be taken care of. alBadri, by contrast, often downplays his power and emphasises his humble "fellow citizen" status. He jokes with callers and plays along with their subtle criticism of government agencies. (Crucially, these effects are not rooted in broadcaster performance alone: callers also play along with the selfpresentation of both broadcasters, making it a properly dialogic phenomenon.) 


\section{The theoretical problem: from linguistic anthropology to media studies}

But while the linguistic anthropological method offered interesting analytical conclusions, these still required some sort of theoretical framework in which the differences between the two broadcasters could be understood more broadly. In the final analysis, I borrowed this from media studies: specifically, the concept of persona. Media studies scholars such as Christine Gledhill and Andrew Tolson have written about the role of persona in the film and television industries, respectively. [Gledhill 1991; Tolson 2001] In this body of work, "persona" is a construct which attempts to convey authenticity of a person's individual character - but an authenticity which is performed: it is individual personality, characterological quirks, insofar as it emerges through linguistic performance in a mass medium, in public rather than in private space.

This is a congenial concept to describe the differences between al-Wakeel and al-Badri. Their language, while similar on a sociolinguistic level, is nevertheless used to construct two quite distinct characters on their radio programmes. al-Wakeel is a highly agentive problem-solving "hero," who engages with his audience in a classic form of disbursing top-down assistance through patronage; al-Badri is a more downto-earth ordinary citizen, with limited power, who jokes with his callers and engages with them on a more equal level.

5. Discussion and conclusion: the broader relevance of an interdisciplinary study of media language 
My analysis of Jordanian service programmes thus provides an example of an interdisciplinary approach to media texts - including theory and methods from sociolinguistics (through the variationist analysis of broadcaster language); linguistic anthropology (comparative analysis of programmes as "units of interaction); and media studies (the concept of persona).

What is the unique scholarly contribution made by such an approach? First, it explores "language" in a way that takes better account of the performance context than classical sociolinguistic variationist approaches. Such approaches focus predominantly on variation and neglect the fact that speakers may use this variation strategically for particular purposes, which differ across instances of language use. Second, this approach also allows us to appreciate the broader social and political implications of specific linguistic practices and strategies. It can uncover nuances and distinctions, such as contrasts in persona, which impact the inclusivity and participation in mass media - members of the public addressed as, and participating as, "clients" in al-Wakeel's show, while participating on a more equal level in al-Badri's, for example.

One challenge of this approach lies in choosing data and material that is amenable to multi-stranded interdisciplinary analysis. My approach relied heavily on transcripts, as opposed to e.g. interviews or field observation. Transcripts conceal the actual spaces of production and consumption; alternative methods may have offered different arguments for the relevance of language use. It also runs the risk of sacrificing methodological rigorosity, as defined by each individual discipline, in favour of a more sweeping examination with a less clearly defined focus. "Following through" with a single methodological line would take advantage of "quality-assured" research 
procedures and accounting for biases, as well as sustained scholarly conversations on common ground with existing disciplinary experts.

Nevertheless, I argue that setting the scope more broadly is productive in the case of analysing Jordanian radio programmes. My study demonstrates that aspects of language, and persona in particular, have broader relevance for audience inclusivity, as well as the basis on which listeners are allowed to participate when they call-in. An interdisciplinary approach, therefore, reveals important aspects of media communication in the contemporary Middle East which may be neglected when the topic is approached through a single disciplinary lens. 


\section{References}

Al-Mahadin, Salam. "Gendered Soundscapes on Jordanian Radio Stations." Feminist Media Studies, 2016.

al-Wer, Enam. "The Formation of the Dialect of Amman." In Arabic in the City: Issues in Dialect Contact and Language Variation, edited by Catherine Miller, Enam al-Wer, Dominique Caubet, and Janet C. E. Watson, 55-76. London \& New York: Routledge Curzon, 2007.

Du Bois, John W. "The Stance Triangle." In Stancetaking in Discourse: Subjectivity, Evaluation, Interaction, edited by Robert Englebretson, 139-82. Amsterdam: John Benjamins, 2007.

Gledhill, Christine. "Signs of Melodrama." In Stardom: Industry of Desire, edited by Christine Gledhill, 207-29. London \& New York: Routledge, 1991.

Philips, Susan. "Method in Anthropological Discourse Analysis: The Comparison of Units of Interaction." Journal of Linguistic Anthropology 23, no. 1 (June 2013): 82-95.

Tolson, Andrew. "'Being Yourself': The Pursuit of Authentic Celebrity." Discourse Studies 3, no. 4 (2001): 443-57. 